\title{
Effects of Climate Change on Wind-Driven Heavy-Snowfall Events over Eastern North America
}

\author{
TYLER P. JANOSKI ${ }^{\mathrm{a}}$ \\ NOAA/Geophysical Fluid Dynamics Laboratory, Princeton, and Department of Environmental Sciences, Rutgers, \\ The State University of New Jersey, New Brunswick, New Jersey
}

\begin{abstract}
ANTHONY J. BROCCOLI
Department of Environmental Sciences, and Institute for Earth, Ocean, and Atmospheric Sciences, Rutgers, The State University of New Jersey, New Brunswick, New Jersey
\end{abstract}

SARAH B. KAPNICK

NOAA/Geophysical Fluid Dynamics Laboratory, Princeton, New Jersey

NATHANIEL C. JOHNSON

NOAA/Geophysical Fluid Dynamics Laboratory, and Atmospheric and Oceanic Sciences Program, Princeton University, Princeton, New Jersey

(Manuscript received 10 November 2017, in final form 7 August 2018)

\begin{abstract}
Eastern North America contains densely populated, highly developed areas, making winter storms with strong winds and high snowfall among the costliest storm types. For this reason, it is important to determine how the frequency of high-impact winter storms, specifically, those combining significant snowfall and winds, will change in this region under increasing greenhouse gas concentrations. This study uses a high-resolution coupled global climate model to simulate the changes in extreme winter conditions from the present climate to a future scenario with doubled $\mathrm{CO}_{2}$ concentrations (2XC). In particular, this study focuses on changes in high-snowfall, extremewind (HSEW) events, which are defined as the occurrence of 2-day snowfall and high winds exceeding thresholds based on extreme values from the control simulation, where greenhouse gas concentrations remain fixed. Mean snowfall consistently decreases across the entire region, but extreme snowfall shows a more inconsistent pattern, with some areas experiencing increases in the frequency of extreme-snowfall events. Extreme-wind events show relatively small changes in frequency with $2 \mathrm{XC}$, with the exception of high-elevation areas where there are large decreases in frequency. As a result of combined changes in wind and snowfall, HSEW events decrease in frequency in the 2XC simulation for much of eastern North America. Changes in the number of HSEW events in the 2XC environment are driven mainly by changes in the frequency of extreme-snowfall events, with most of the region experiencing decreases in event frequency, except for certain inland areas at higher latitudes.
\end{abstract}

\section{Introduction}

Snowfall is an important meteorological variable with significant impacts on human life, including water resource management and transportation. With one-sixth

\footnotetext{
${ }^{\text {a }}$ Current affiliation: Department of Earth and Environmental Sciences, Columbia University, New York, New York.

Corresponding author: Tyler P. Janoski, janoski@ldeo.columbia.
} edu of the world's population dependent on snowmelt for water, consistent annual snowfall is vital for many regions (Vavrus 2007). It is also one of many variables expected to change with increasing atmospheric greenhouse gas concentrations (e.g., Kapnick and Delworth 2013; Krasting et al. 2013; O'Gorman 2014; Danco et al. 2016). As global mean surface temperature increases, it follows that snow will account for a smaller proportion of precipitation compared to rainfall (O'Gorman 2014). This relationship, however, is complicated by the expectation that total precipitation amounts will change 
with greater atmospheric water vapor content as the climate warms, rendering snowfall's response to increasing temperatures ambiguous (O'Gorman and Schneider 2009). It has been shown that most areas in the midlatitudes will likely experience less annual snowfall with increased atmospheric greenhouse gas concentrations (Kapnick and Delworth 2013; Krasting et al. 2013; O'Gorman 2014).

Extreme snowfall, which poses risks to human life and property, likewise may change in the future climate. Blizzards in particular, which combine heavy snowfall with high winds, are among the most destructive and costly snowfall events (NWS 2016a; Changnon 2007). They can cause power outages, severely disrupt transportation, and impede emergency services. A change in blizzard frequency therefore would have significant impacts on snow removal, urban planning, and the transportation industry, among others. After dividing the continental United States into nine climate districts, Changnon (2007) found that catastrophic winter storms caused the four easternmost districts more than \$26 billion in damage from 1949 to 2003, which accounts for $\sim 74 \%$ of total snowstorm losses for the country. The eastern United States is especially susceptible to these storms because of high population density and infrastructure development.

Although blizzards clearly have severe societal impacts, their classification presents some challenges owing to subjectivity in the criteria used to define blizzards. The National Weather Service defines a blizzard as a $\geq 3$-h period with sustained winds or frequent gusts of $35 \mathrm{mph}$ or greater, considerable falling or blowing snow, and visibility frequently reduced to less than $0.25 \mathrm{mi}$ (NWS 2016b). The term "considerable" has an ambiguous meaning that does not connote a rigid snowfall threshold that must be met for a storm to be considered a blizzard; "considerable" is dependent on the human perception of those impacted by the storm. Recently, NOAA's National Centers for Environmental Information began classifying snowstorms in the eastern twothirds of the United States using the regional snowfall index, which is region dependent and defines the spatial impact of storms, but does not take wind into account (Squires et al. 2014). Other countries' meteorological organizations have varying definitions of blizzards, some of which are similarly dependent on the region impacted (e.g., Environment and Climate Change Canada 2016). Historical analyses of blizzards have used widely varying definitions of blizzards-including measures of storm reports (Schwartz and Schmidlin 2002); combinations of snow, wind, and wind chill (Lawson 2003); and frozen precipitation extremes (Jiang et al. 2013; Kunkel et al. 2009)—exemplifying the ambiguity of the NWS definition and the need for a standard definition that can be used with both station observations and reanalysis data and climate model output.

Observational snowfall data in the eastern United States are available from sources such as the U.S. National Weather Service Cooperative Observer Program (COOP). A new gridded snowfall product is available that incorporates in situ observations and was originally developed and tested for seasonal and interannual variability but is relatively low resolution, so it must be used carefully over complex topography and for regional extremes (Kluver et al. 2016). Direct observations of snowfall accumulation in the eastern United States have limited lengths of record and spatial coverage. Snow density itself is not a static variable (Roebber et al. 2003), further complicating its use for climate variability and climate change studies across areas with different climate characteristics (e.g., temperature, humidity, cloud formation). As a result, snow depth observations may not prove to be adequate for regional analyses of extreme-snowfall event magnitude, frequency, or response to climate change. Climate models can be used to address this data gap to quantify snowfall-related extremes in the present and future climate provided that the climate models can realistically simulate the processes that drive extreme snowfall.

Global climate models (GCMs) have been used in several recent studies to determine potential changes in mean snowfall in the future. Krasting et al. (2013) used 18 coupled atmosphere-ocean GCMs from phase 5 of the Coupled Model Intercomparison Project (CMIP5) to analyze snowfall trends in the Northern Hemisphere under the RCP4.5 emissions pathway and found decreases in annual snowfall for much of the midlatitudes where increases in temperature decrease the proportion of precipitation falling as snow. Kapnick and Delworth (2013) used high- and low-resolution global climate models (with the high-resolution model resolving topography better than in CMIP5 models) and found similar trends as Krasting et al. (2013) in that with increasing atmospheric $\mathrm{CO}_{2}$ concentrations, annual snowfall decreases from the low to midlatitudes and increases in the high latitudes, as well as in some highaltitude regions. In regions with snowfall increases, the effect of increased total precipitation during the cold season dominates the rise in surface temperature. Snowfall extremes have also been examined in the climate models of the CMIP5 archive; these studies find that the frequency of daily snowfall events globally decreases with increasing $\mathrm{CO}_{2}$ concentrations but with increases in heavy-snowfall events in some areas even where the average snowfall decreases (Danco et al. 2016), highlighting an uneven response in mean versus 
extreme snowfall (O’Gorman 2014). Notaro et al. (2014) used statistical downscaling on relatively coarse GCM output and found that over eastern North America, mean snowfall decreases but the average intensity of snowfall events increases. Kawase et al. (2016) found similar results, including decreases in mean snowfall but increases in extreme daily snowfall in some areas of Japan, using an ensemble of high-resolution climate models.

Although these recent studies indicate progress in understanding how both mean and extreme snowfall will change with increasing greenhouse gases, it remains uncertain how these results would apply to blizzards or blizzard-like extreme winter storms. Winds in relation to snowfall have not been analyzed in future climate simulations, leaving projections of the frequency of winddriven extreme-snowfall events in the future climate unclear without further research.

\section{Data and methodology}

\section{a. Datasets and model output}

To detect robust changes in extreme snow and wind events in the future climate, a GCM was used to generate long simulations spanning several hundred years. This study uses the Forecast-Oriented Low Ocean Resolution model (FLOR; Vecchi et al. 2014), sharing the same high-resolution atmosphere used in Kapnick and Delworth (2013). FLOR is derived from the GFDL Climate Model 2.5 (CM2.5; Delworth et al. 2012) and uses similar physics schemes as CM2.5 but has increased horizontal and vertical resolution of the atmosphere and an improved land model shared with CM2.5 (Milly et al. 2014). The model's horizontal resolution of the atmosphere and land is approximately $50 \mathrm{~km}$ with 32 atmospheric vertical levels. This land resolution provides a topographical gradient for the Appalachian Mountains (Fig. 1), otherwise absent or severely flattened in lowerresolution models typical of those contributed to CMIP5; an elevation gradient is important for regional precipitation extremes (van der Wiel et al. 2016). Unlike CM2.5, the horizontal resolution of ocean and sea ice components is reduced to approximately $1^{\circ}$ for the sake of computational efficiency. FLOR has been previously employed in studies of extratropical storms and precipitation predictability and extremes (Yang et al. 2015; Jia et al. 2015; van der Wiel et al. 2016).

Two FLOR simulations were conducted: a 1990 control and a $\mathrm{CO}_{2}$ doubling (2XC) experiment. The 1990 control maintains greenhouse gas, ozone, and aerosol concentrations at 1990 levels and was run for 1505 years. The availability of this long integration aids in our ability to calculate the statistical significance of extreme events.
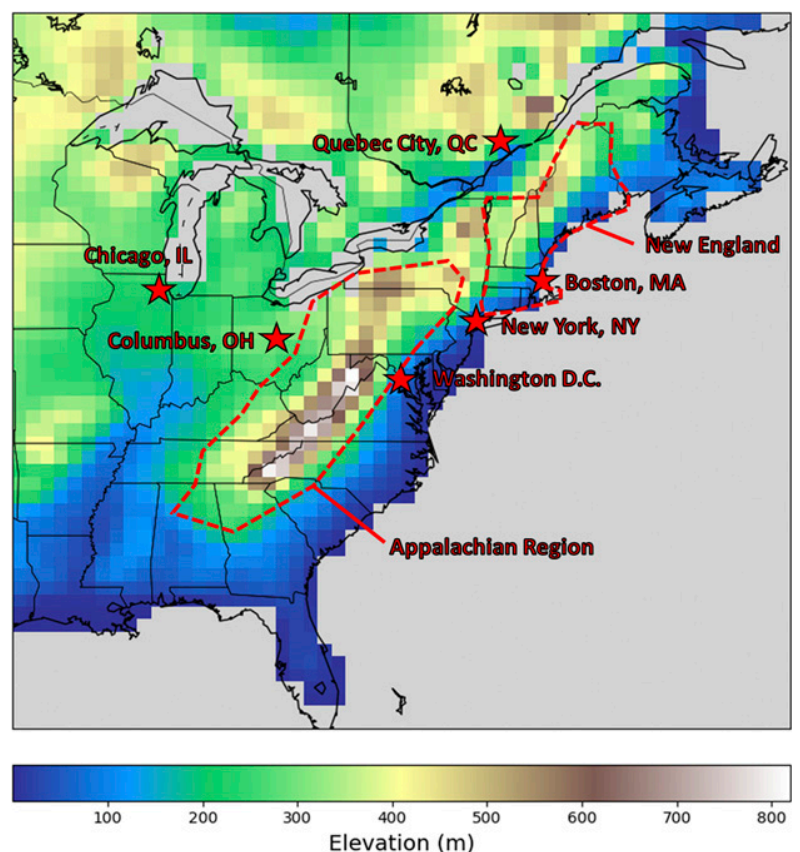

FIG. 1. Map of elevation (m) in the CM2.5 FLOR. Certain regions repeatedly referenced are outlined in a dashed red line. Cities whose snowfalls are more closely examined later in the study are labeled and marked with red stars. Ocean and lake grid boxes (with less than $50 \%$ land) are masked in gray.

The 2XC simulation used initial conditions from year 101 in the 1990 control simulation and imposed a $1 \% \mathrm{yr}^{-1}$ increase in $\mathrm{CO}_{2}$ until the concentration is doubled relative to 1990 levels after 70 years. The $2 \mathrm{XC}$ simulation was then run for 330 years with the concentration of $\mathrm{CO}_{2}$ held constant (years 171-500).

Snowfall was provided in the form of daily liquid equivalent of frozen precipitation rate $\left(\mathrm{kg} \mathrm{m}^{-2} \mathrm{~s}^{-1}\right)$, which we then converted into daily liquid equivalent of frozen precipitation assuming a uniform density of liquid water. FLOR utilizes the Arakawa-Schubert convection parameterization where large-scale supersaturation is condensed into cloud water from which large-scale precipitation fluxes are derived. Large-scale rain and snow fluxes are diagnosed with precipitation fluxes tracked separately inside and outside of clouds according to Jakob and Klein (2000). Snow is formed by the precipitation of cloud ice and accretion processes interacting with cloud liquid water; after formation and falling, snow melts instantaneously if passing through an atmospheric layer above $2^{\circ} \mathrm{C}$. Further details of the microphysics can be found in Rotstayn (1997), while the interactions with the stratiform area (macrophysics) are described in Tiedtke (1993). Full details of convection and other physical choices for parameterization schemes in the atmosphere are provided in Anderson et al. (2004). 
The land surface model used in FLOR is the Land Model, version 3 (LM3), with the same horizontal resolution as the atmosphere (Milly et al. 2014). Lakes in LM3 are characterized by changing depth and vertical profiles of temperature and ice content (lake ice is included in this dynamic modeling). In the Great Lakes, a vertical eddy diffusivity constant is used to parameterize the unresolved effects of three-dimensional mixing. LM3 has a high lake ice bias in the Great Lakes that may reduce evaporation from the surface in this region during the winter months. Further information regarding the land model and biases can be found in Milly et al. (2014).

Mean annual and extreme snowfall in the control run of FLOR was compared to snowfall from two datasets: the Modern-Era Retrospective Analysis for Research and Applications, version 2 (MERRA-2; Gelaro et al. 2017), and the North American gridded snowfall dataset presented in Kluver et al. (2016) and referred to as NorAm. The horizontal spatial resolution of MERRA-2 is $0.5^{\circ} \times 0.625^{\circ}$ latitude by longitude, and this study uses a 25 -yr subset of daily liquid equivalent snowfall rate from 1993 to 2017 for all snowfall calculations. MERRA-2 data were obtained from the NASA Modeling and Assimilation Data and Information Services Center (MDISC) website managed by the NASA Goddard Earth Sciences Data and Information Services Center (https://disc.sci.gsfc. nasa.gov/datasets page $=1 \&$ keywords $=$ MERRA-2). NorAm is a daily gridded $1^{\circ} \times 1^{\circ}$ product for North America derived from station observations that covers the period 1900-2009 and is available through the Rutgers University Global Snow Laboratory website (http:// snowcover.org).

\section{b. Methodology and statistics}

Comparisons of the frequencies of extreme events were based on two 300-yr analysis periods from the 1990 control and 2XC simulations, respectively. The latest 300 -yr period available from the $2 \mathrm{XC}$ experiment (i.e., years 201-500) was used for comparisons to the control run. Ideally, the analysis period for the 1990 control simulation would begin 101 years after the time at which the 2XC simulation was initialized to reduce the effects of any climate drift. Unfortunately, daily output is not available from the first 400 years of the control simulation because of processing failure, leaving only years 401-1505 to compare with the $2 \mathrm{XC}$ experiment. The earliest 300-yr period available (i.e., years 401-700) was therefore used for calculating changes in high-snowfall, extreme-wind (HSEW) events.

To establish the statistical significance of changes between the 1990 control and the 2XC experiment, a block bootstrap is performed with all available control years. Because of a processing error, six 5-yr periods were missing from the record, leaving a total of 1075 control years to sample from. For all statistical significance tests, a random subsample of 300 years from the entire control is chosen with replacement, and the desired quantity is calculated on the subsample. This procedure is repeated 10000 times to produce a frequency distribution of that quantity in the entire control run at each grid point. The change in a quantity is deemed statistically significant at the $5 \%$ level if its value in the 2XC simulation is below the 2.5 percentile value or above the 97.5 percentile value of this distribution.

Unit conversion and regridding of datasets were necessary for validation comparisons. Similar to FLOR, MERRA-2 data were converted from a frozen precipitation rate to a daily liquid equivalent snowfall value. NorAm contains daily snowfall measured as snow depth (not liquid equivalent depth or rate). Because snowfall in FLOR and MERRA-2 is in liquid equivalent, NorAm must be converted from snow depth value to a liquid equivalent value. We have chosen to use a constant snowto-water ratio of 12.5:1 depth-to-liquid ratio based on climatological values presented in Baxter et al. (2005). For comparisons at a uniform resolution, data from FLOR and MERRA-2 were regridded using linear interpolation to have the same coarser resolution of NorAm $\left(1^{\circ} \times 1^{\circ}\right)$.

It is not feasible to apply an operational definition of a blizzard to model output because of the temporal and spatial resolution that limit the ability to capture necessary blizzard ingredients, such as wind gusts. It is also apparent that different studies use varying definitions of blizzards depending on the type of data used (Schwartz and Schmidlin 2002; Lawson 2003; Kunkel et al. 2009; Jiang et al. 2013). In this study, "blizzard-like" events are defined as joint occurrences of heavy snow and extreme wind since the combination of both is capable of producing significant human impacts. It follows that by selecting a reasonable threshold for snowfall and an extreme value for winds, a blizzard-like storm or HSEW event may be characterized from model output. This study defines an HSEW event as a 2-day period meeting the following criteria:

- snowfall greater than or equal to $2.5-\mathrm{cm}$ liquid equivalent and

- 6-hourly average 10-m winds exceeding the 1990 control's 98th percentile of 2-day maximum 6-hourly wind speed.

Because the model output is archived by calendar day, a 2-day period was used rather than a single day to account for snowfall events that extend into two different days, which avoids a bias against storms that begin near the end of a day. The contribution of blowing snow was also considered in picking this time frame, as high winds over freshly fallen snow can also cause blizzard 

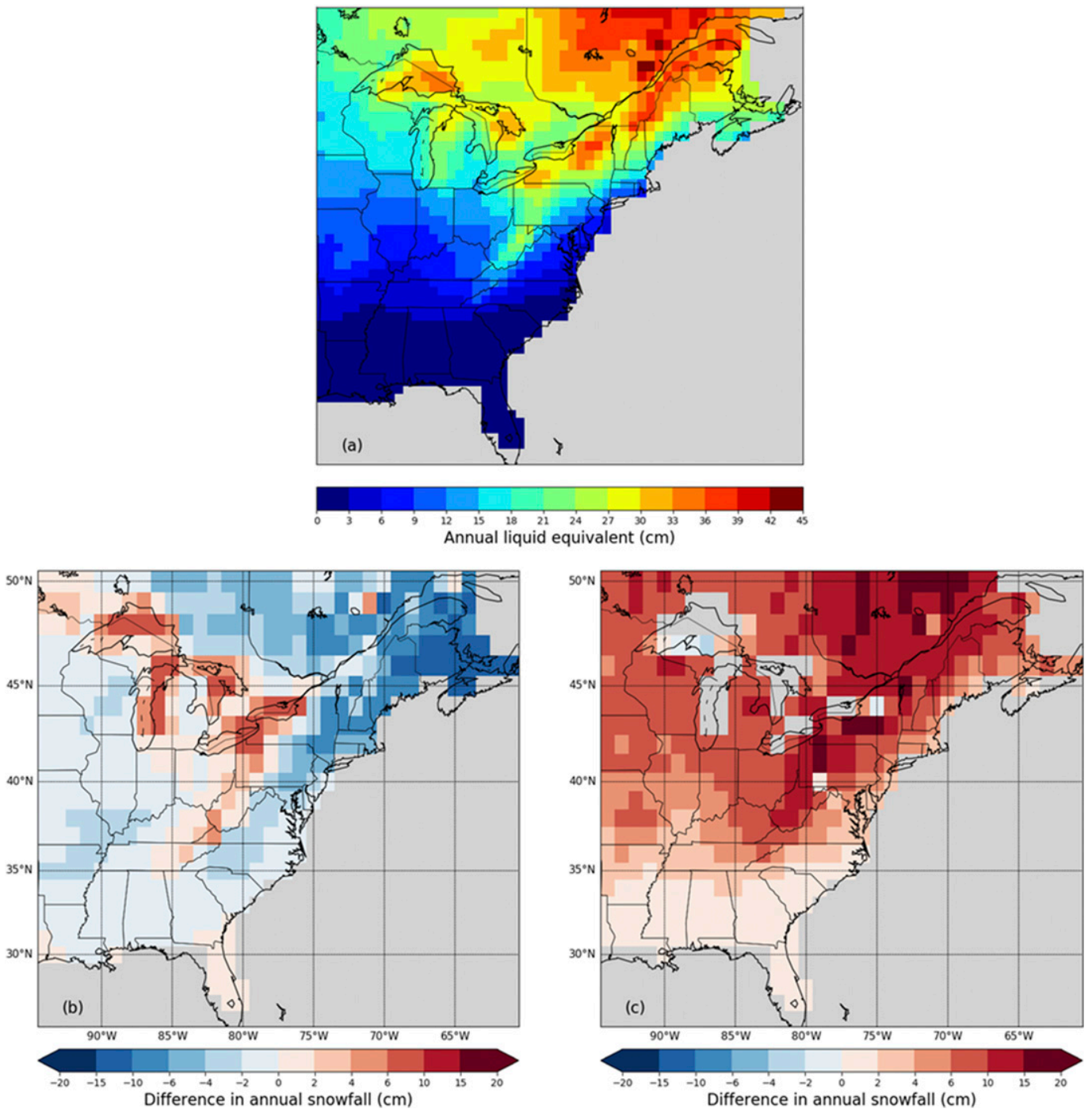

FIG. 2. (a) The mean annual snowfall ( $\mathrm{cm}$ liquid water equivalent) in the FLOR control run in FLOR's native $50 \mathrm{~km} \times 50 \mathrm{~km}$ resolution. (b) The difference in mean annual snowfall between the FLOR control and MERRA-2 (cm liquid water equivalent), with areas in red signifying more annual snowfall in FLOR. (c) As in (b), but for the difference between FLOR and the NorAm dataset.

conditions (NWS 2016b). The 2.5-cm liquid equivalent for snowfall threshold was chosen to signify extreme 2-day snowfall capable of human impact. Given the assumed depth-to-liquid ratio of $12.5: 1$, this is equivalent to $31.25 \mathrm{~cm}$ (12.3 in) of snow depth, which is enough to disrupt transportation and require $12+\mathrm{h}$ of snow removal (Tucker and Clohan 1979). An extreme percentile of 2-day maximum 6-hourly winds based on the 1990 control was used rather than a uniform wind threshold because of variations in the model's surface roughness that affect simulated $10-\mathrm{m}$ wind speeds. A sensitivity analysis was performed to ensure that the changes in blizzard frequency were not overly dependent on the specific snow and wind thresholds chosen.

\section{Results}

\section{a. Validation of mean climatology}

Figure 1 highlights a few areas repeatedly referenced in the study as well as identifies several cities whose snowfall is more closely examined. Before analyzing differences between mean and extreme snowfall in the 1990 control and the $2 \mathrm{XC}$ run, we compared mean annual snowfall in the control to mean annual snowfall in MERRA-2 and NorAm. The mean annual snowfall liquid equivalent for the FLOR 1990 control is shown in Fig. $2 \mathrm{a}$ in FLOR's native $50 \mathrm{~km} \times 50 \mathrm{~km}$ horizontal resolution. Local maxima located in upstate New York and Michigan are consistent with the spatial distribution 
of lake-effect snow in the northern United States. Mountainous areas, such as the Appalachians, also contain higher annual snowfall amounts compared to surrounding lowland areas, as would be expected with high elevation and lower wintertime temperatures. Figure $2 b$ shows the difference between mean annual snowfall in the FLOR control run and in the 25-yr subset of MERRA-2. FLOR has a considerably higher mean annual snowfall in the Great Lakes and Appalachian regions, with the difference exceeding $10-\mathrm{cm}$ liquid equivalent in some grid boxes. MERRA-2's annual snowfall is greater than that of FLOR for much of the eastern United States and southeastern Canada. FLOR appears to produce more snow in colder, higherelevation areas than MERRA-2, as well as in areas prone to lake-effect snow. Figure $2 \mathrm{c}$ shows the difference between FLOR and NorAm. With the exception of the Upper Peninsula of Michigan, FLOR produces significantly more annual snowfall than what is recorded in the NorAm. The largest differences are present in Pennsylvania and New York; in these lake-effect-prone areas, climatological snow water equivalent ratios exceed 15:1, implying the 12.5:1 may be underestimating the true magnitude of differences between FLOR and NorAm (Baxter et al. 2005). One reason FLOR and NorAm may differ considerably is a cold and wet bias in FLOR, with mean temperatures in the study region $1^{\circ}-5^{\circ} \mathrm{C}$ colder and up to $1 \mathrm{~mm}$ day $^{-1}$ more annual mean precipitation than observations for the study region ( $\mathrm{Jia}$ et al. 2015), thus producing a snowfall bias. Observational snowfall data also suffer from snowfall undercatch, with $20 \%-50 \%$ of snowfall not recorded by typical precipitation gauges (Rasmussen et al. 2012). Direct comparisons between both NorAm and MERRA-2 data to FLOR output are further made difficult because realworld data, which have forcings that change over time, are being compared to output from a constant-forcing simulation. The differences between FLOR, MERRA-2, and NorAm attest to the variation in a measured quantity such as snowfall between output from a climate model or reanalysis or from an observational dataset.

\section{b. Control simulation extremes}

This study's definition of an HSEW event requires a 2-day snowfall of $\geq 2.5 \mathrm{~cm}$, and Fig. 3a shows the annual frequency of snowfall events meeting this threshold in FLOR in its native resolution. Only unique 2-day periods are shown to avoid some events being counted twice. Maxima in annual snowfall shown in Fig. 2a tend to have a corresponding maximum in Fig. 3a because of the contribution of frequent high-snowfall events to the mean annual snowfall, but this is not true everywhere. Areas in the northeastern United States and southeastern Canada have more than 1.5 high-snow events per year where nor'easter-type storms commonly produce significant snowfall. Further inland, increased distance from moisture sources, such as the Atlantic Ocean, makes these events more infrequent. To compare high-snow event frequency in FLOR to that of MERRA-2 and NorAm, the average annual unique high-snow event frequency was calculated for each of the datasets, with FLOR and MERRA-2 being regridded to the coarser NorAm resolution. The difference in average annual high snowfalls between FLOR and MERRA-2 and FLOR and NorAm are shown in Figs. $3 b$ and $3 c$, respectively. For much of the region of interest, MERRA-2 has a higher annual frequency of high-snow events, especially in the northeastern United States and southeastern Canada. This spatial pattern is quite different to that of Fig. 2b, where FLOR is shown to produce slightly more annual liquid equivalent snowfall on average in the Great Lakes and Appalachian regions, implying that FLOR may have a higher frequency of smaller-snowfall events, below the $2.5-\mathrm{cm}$ threshold, that contribute to the total annual snowfall in those regions. Figure $3 \mathrm{c}$ is spatially similar to Fig. 2c, with FLOR exceeding NorAm in annual high-snowfall frequency over the entire region, with the exception of several grid boxes in New York and Michigan. High snowfalls matching this study's definition are relatively infrequent in NorAm, including areas typically associated with large-snowfall events. Kluver et al. (2016) notes that the majority of grid cells with Community Collaborative Rain, Hail and Snow Network stations have a negative average error, indicating NorAm snowfall is lower than observations in those locations. While the FLOR control does show considerable differences in climatological extremes when compared to MERRA-2 and NorAm, the differences between MERRA-2 and NorAm, two products that incorporate observational data, are greater. Therefore, FLOR falls within the range of observational estimates for highsnowfall event frequency.

Because the wind threshold is based on an extreme percentile of the 6-hourly average $10-\mathrm{m}$ wind, the frequency of the threshold being met is the same for all grid boxes. HSEW event frequency is therefore dependent on qualifying high-snow events occurring in the same 2-day period as winds exceeding the 98th percentile. Figure 4a shows the annual HSEW event frequency in the FLOR control run. The spatial distribution of the annual HSEW event frequency closely matches that of the $\geq 2.5-\mathrm{cm}$ event frequency, albeit with decreased frequencies, as would be expected with the introduction of the wind threshold. Coastal New England and southeastern Canada contain the highest HSEW event 

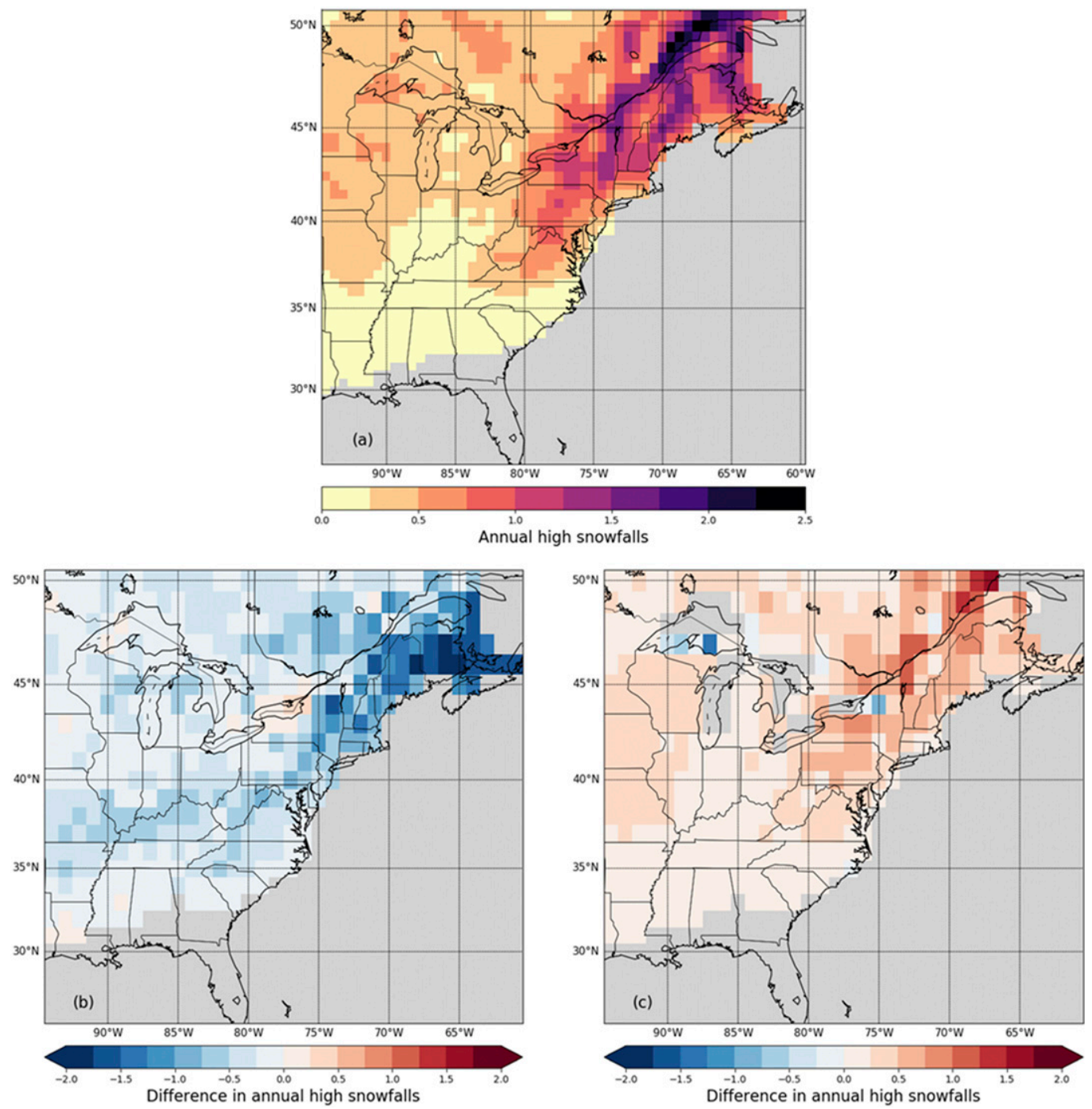

FIG. 3. (a) The annual frequency of unique 2 -day periods with snowfall $\geq 2.5$-cm liquid equivalent in the control run. This amount reflects the snowfall threshold to be classified as an HSEW event. (b) The difference in the average annual number of high snowfalls between FLOR and MERRA-2, with areas shaded red indicating a higher frequency in FLOR. (c) As in (b), but for the difference between FLOR and NorAm datasets. Grid boxes with $\leq 5$ high-snowfall events in the 300-yr FLOR control run and ocean points are masked.

frequencies. In this area, large snowfalls usually result from powerful coastal storms that are associated with extreme winds, producing higher counts in HSEW events compared to other parts of the United States. The grid box containing Boston, Massachusetts, experiences approximately one HSEW event per year in the control run, while the Chicago, Illinois, grid box experiences one event every two years.

To analyze what proportion of qualifying $\geq 2.5-\mathrm{cm}$ liquid equivalent 2-day snowfalls also meet the wind threshold, we show in Fig. 4b the ratio of qualifying snowfalls to HSEW events in the 1990 control run. Over much of the region, the ratio varies from 0.4 to 0.8 , meaning that $40 \%-80 \%$ of the qualifying 2 -day snowfalls also have 2-day maximum 6-hourly winds that meet or exceed the control's 98th percentile. Many of the highest values occur along the U.S. East Coast, where heavy snowfall is associated with strong and rapidly developing storms. There is also a region of high ratios across the upper Midwest, signifying that heavy snowfalls in this area are often accompanied by winds exceeding this study's threshold. A noteworthy exception is the Appalachian region, spanning from West Virginia to Georgia. In this area, ratios are often $<0.4$, implying that high-snowfall and extreme-wind events coincide less frequently than in other areas considered in this study. This may be because persistent orographic effects can cause heavy snowfall in mountainous 

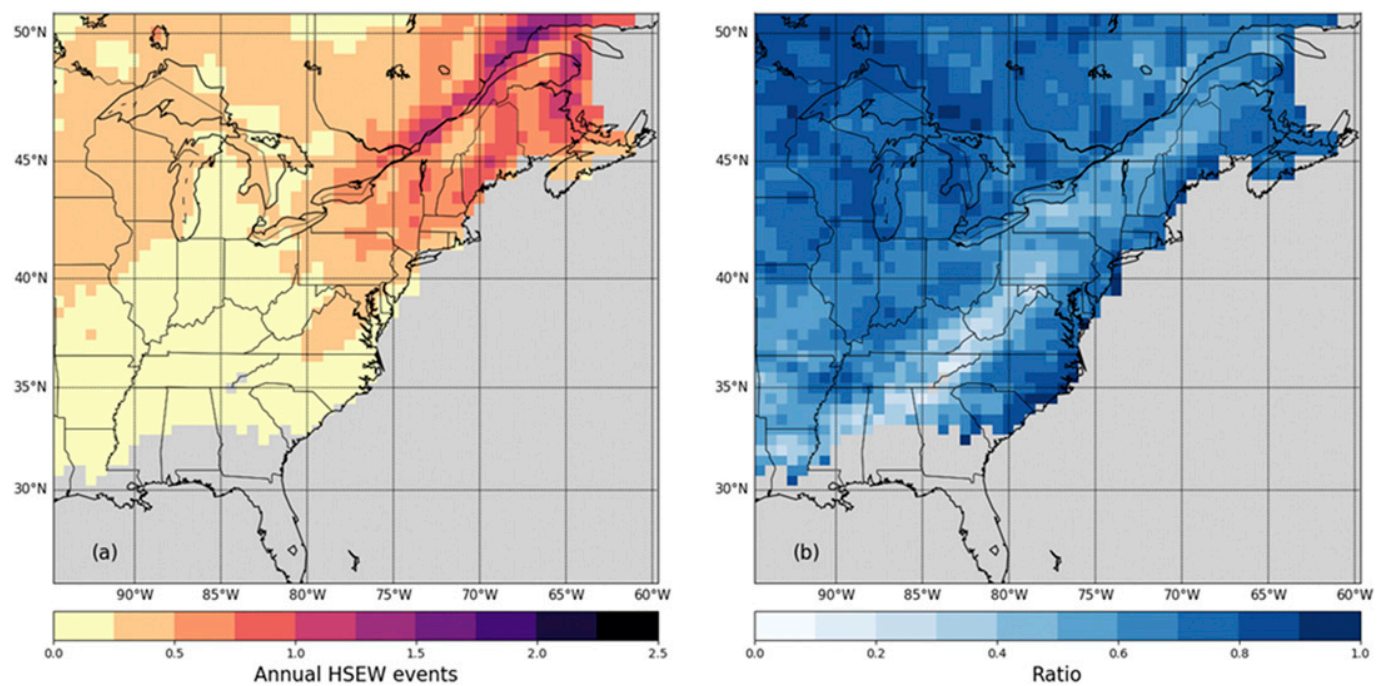

FIG. 4. (a) The annual frequency of HSEW events in the control run, defined as a unique 2-day period with snowfall $\geq 2.5-\mathrm{cm}$ liquid equivalent and one period of 6-hourly average winds exceeding the 98th percentile. (b) The ratio of the number of HSEW events to the number of $\geq 2.5$-cm liquid equivalent 2-day snowfalls. Grid boxes with $\leq 5$ HSEW events in the 300-yr control run and ocean points are masked.

regions, including the Appalachians, even in the absence of deep cyclones with strong winds. It may also be caused by the occurrence of extreme-wind events unassociated with high snowfalls.

\section{c. Responses to $\mathrm{CO}_{2}$ doubling}

The control run, which uses atmospheric constituents kept constant at 1990 levels, was then compared to the 300 -yr simulation of the $2 \mathrm{XC}$ experiment. Changes in snowfall result from changes in precipitation as well as the fraction of precipitation that falls as snow. Examining how average temperature and precipitation change with $\mathrm{CO}_{2}$ doubling can provide insight into this relationship, especially in the cold season when the majority of snow is expected to occur. Figure 5a shows the change in average $2-\mathrm{m}$ temperature with $2 \mathrm{XC}$ during the cold season, which is defined as 1 October-31 March in this study. All of the study area experienced statistically significant $(p=0.05)$ increases in average $2-\mathrm{m}$ temperature, but there is a clear latitudinal gradient, with
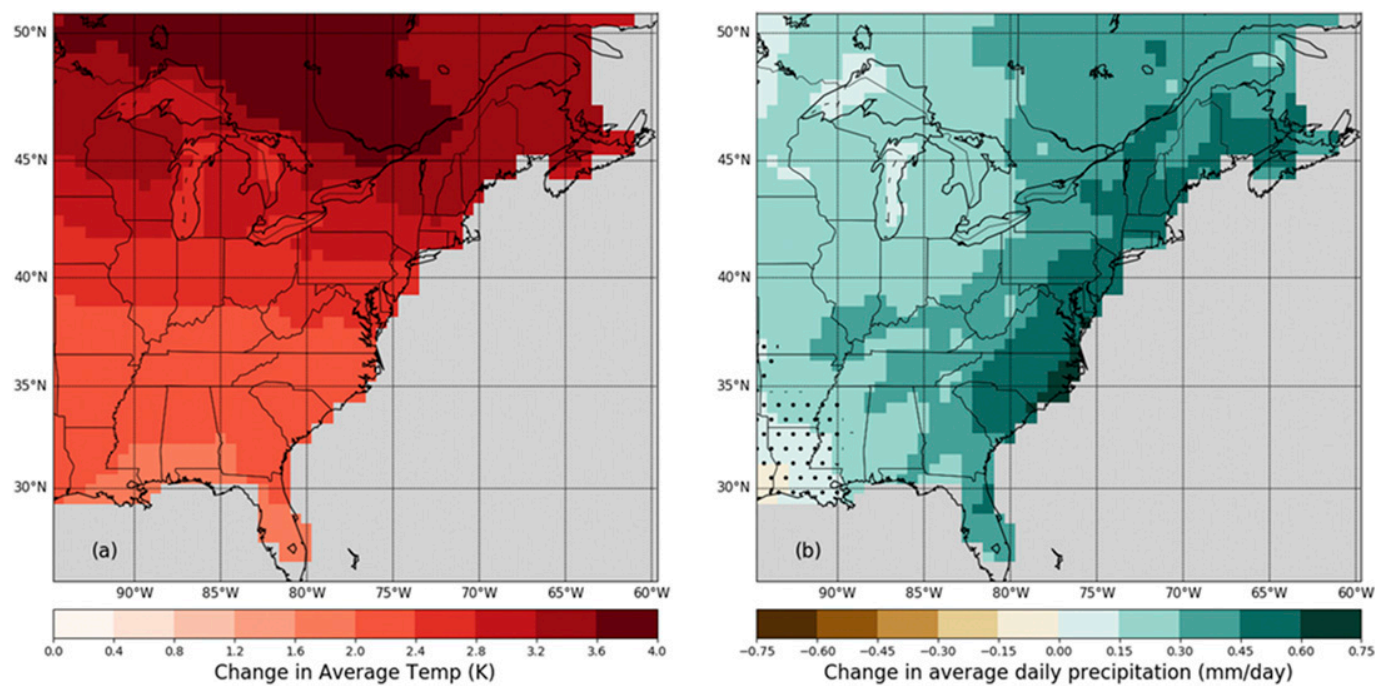

FIG. 5. (a) The change in average cold-season (October-March) temperature with 2XC. (b) The change in average cold-season daily precipitation rate with $2 \mathrm{XC}$. Stippling indicates regions that do not pass a statistical significance test at the $5 \%$ level when compared to the control simulation (see section $2 \mathrm{~b}$ ). Regions that are statistically significant at the $5 \%$ level are left unimpeded. Ocean grid boxes are masked. 
average temperatures in south Florida experiencing 1.6-2.0-K increases while temperatures in central Quebec and Ontario, Canada, increasing more than $3.6 \mathrm{~K}$. The dependence on the magnitude of temperature increases on latitude was found in Manabe and Wetherald (1975), who note snow albedo feedback and vertical stability changes as contributing factors to this gradient with 2XC. There is also some evidence of reduced warming in the Great Lakes region, possibly resulting from the modulation of the temperature increase by the lakes. Figure $5 \mathrm{~b}$ shows the change in average daily precipitation rate with $2 \mathrm{XC}$. The entire study area, with the exception of southwest Louisiana and southeast Texas, experiences increases in average daily precipitation rate, with a maximum in far eastern North Carolina. The spatial distribution of both cold-season temperature and precipitation changes with $2 \mathrm{XC}$ are consistent with those found in the CMIP5 ensemble analyzed in Diffenbaugh and Giorgi (2012). With regard to their relationship with snowfall, the changes in temperature and changes in precipitation are opposing forces: increased cold-season precipitation implies greater snowfall potential, but increased cold-season temperature implies a smaller fraction of total precipitation that falls as snow or other types of frozen precipitation.

Changes in snowfall statistics between the two runs were first determined to compare with the trends obtained in Krasting et al. (2013), Danco et al. (2016), and O'Gorman (2014). Those three studies used an ensemble of CMIP5 models, whereas the CM2.5 FLOR used in this study is of comparatively higher spatial resolution. Nevertheless, the FLOR simulation produces results consistent with past studies of mean snowfall (Krasting et al. 2013; Kapnick and Delworth 2013). Figure 6a shows the change in mean annual snowfall with $\mathrm{CO}_{2}$ doubling. All regions considered in this study show statistically significant decreases in mean annual snowfall. The magnitude of the decrease varies with elevation and latitude, with areas of southeastern Quebec experiencing decreases of $20 \%$ or less and coastal areas of the southeastern United States experiencing decreases of more than $60 \%$. Areas of generally lower cold-season temperatures, including Quebec as well as the Appalachian region of the eastern United States, are hypothesized to experience reduced magnitudes of mean snowfall decreases with increased $\mathrm{CO}_{2}$ because temperatures frequently would remain cold enough to support significant snowfall. As we discuss later, the climatological winter temperature is, in fact, a strong control of mean-snowfall changes in the FLOR simulation.

Extreme percentiles of daily snowfall events were calculated for both the control run and the 2XC experiment, with the percent change shown for the 99.9th, 99.95th, and 99.99th percentiles in Figs. 6b-d, respectively. While the mean annual snowfall consistently shows decreases for the entire study area, extreme snowfall percentiles show areas of increase as well. With the exception of the southeastern United States, the magnitudes of the decreases in extreme snowfall are muted when compared to the decreases in mean snowfall. This is consistent with the results of O'Gorman (2014), who found smaller decreases for higher percentiles of the snowfall distribution. Areas of southeastern Canada experience statistically significant increases in all three extreme percentiles considered, with the area experiencing such increases expanding at higher percentiles. There are increases in the 99.99th snowfall percentile in other high-elevation and high-latitude areas, such as eastern West Virginia and northern New England.

The 50-km horizontal resolution of land and atmosphere in FLOR provides an advantage over lowerresolution models in examining local changes in snowfall with increased greenhouse gas (GHG) forcing. The histograms in Fig. 7 show how the frequency of daily snowfalls of varying intensities changes in the $2 \mathrm{XC}$ run of FLOR for grid points that contain major North American cities. Daily snowfall is used in these comparisons to avoid 2-day snowfalls where back-to-back instances may fall into two different bins. The largest decreases for all cities considered are for smaller, more common daily snowfalls because they are the most numerous in the control run to begin with. In every city, there is an intensity threshold such that larger daily snowfall events actually increase in frequency with $2 \mathrm{XC}$. For example, in Fig. 7a, daily snowfalls $\geq 4.5-\mathrm{cm}$ liquid equivalent become more common in the $2 \mathrm{XC}$ run, whereas snowfalls below $4.5 \mathrm{~cm}$ uniformly decrease. The statistical significance of the change in sign in frequency changes at higher intensities cannot be established because of the small numbers of events, but such changes are not unique to this study. Looking at all of the CMIP5 models, Danco et al. (2016) found similar changes for Japan, central and southern Europe, and several other regions in the Northern Hemisphere. This result is also found by Kawase et al. (2016) in Japan for inland grid points.

After inspecting changes in snowfall alone, we may now include the wind component and compare the frequency of HSEW events before and after doubling of $\mathrm{CO}_{2}$. The percent change in HSEW event frequency before and after 2XC is shown in Fig. 8a. Southern and coastal areas experience the strongest decreases in HSEW events, with relatively weaker decreases located elsewhere in the United States. Southeastern Canada likewise experiences statistically significant increases in HSEW frequency, especially in areas that experienced increases in extreme snowfall in Fig. 6. HSEW event 

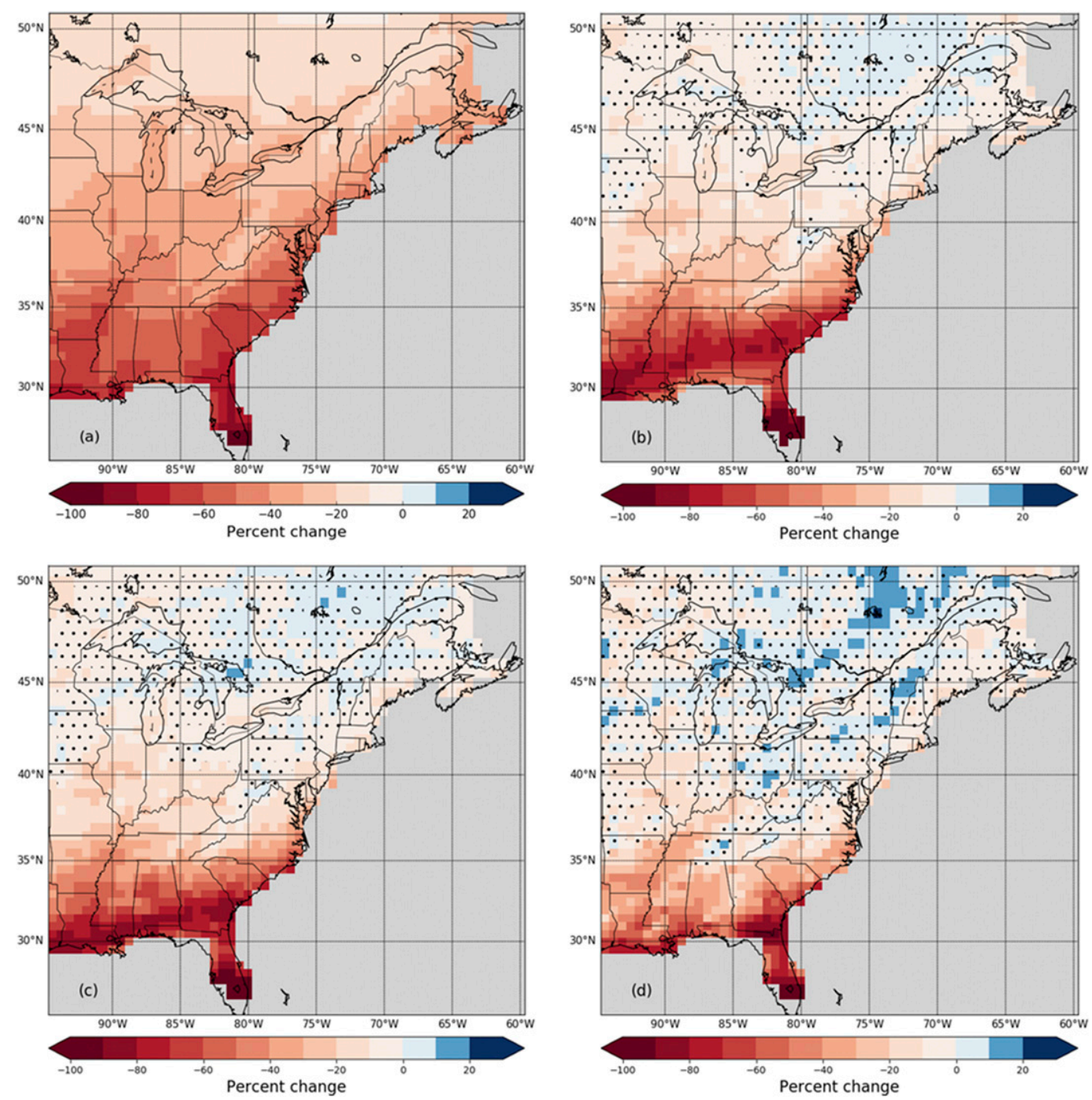

FIG. 6. (a) The change in mean annual snowfall with $\mathrm{CO}_{2}$ doubling. (b) The change in the 99.9th percentile of daily snowfall with $\mathrm{CO}_{2}$ doubling. (c) As in (b), but for the 99.95th percentile. (d) As in (b), but for the 99.99th percentile. Stippling indicates regions that do not pass a statistical significance test at the $5 \%$ level. Note that grid boxes where the control values are 0 as well as ocean points are masked in gray.

frequency in high-elevation areas, such as in Virginia and West Virginia, tends to experience smaller decreases in frequency compared to surrounding lowlands. The change in the total number of HSEW events between the two 300-yr periods is depicted in Fig. 8b. Decreases are generally low in the south because of the already rare occurrences of HSEW events in the control simulation. The greatest absolute decreases in HSEW events occur in coastal New England, where decreases of more than 2.5 HSEW events per decade are present from a swath spanning from Boston to Augusta, Maine. These large decreases result from a considerable percent decrease from Fig. 8a and relatively high HSEW event frequency in the control.
To explore the causes of the changes in HSEW event frequency, it is useful to examine changes in the frequency of threshold exceedance for the two HSEW criteria individually. The change in frequency of 2-day snowfalls meeting or exceeding $2.5 \mathrm{~cm}$ of liquid equivalent is shown in Fig. 9a. The spatial distribution of the changes is similar to the changes in extreme percentiles of daily snowfall depicted in Figs. 6b-d. Decreases in frequency peak in southern and coastal areas, where the increase in average surface temperature may eliminate many of the potential high-snowfall events. Southeastern Canada shows increases in the frequency of $\geq 2.5-\mathrm{cm}$ liquid equivalent events, with other higher-latitude locations showing the smallest decreases in frequency. 

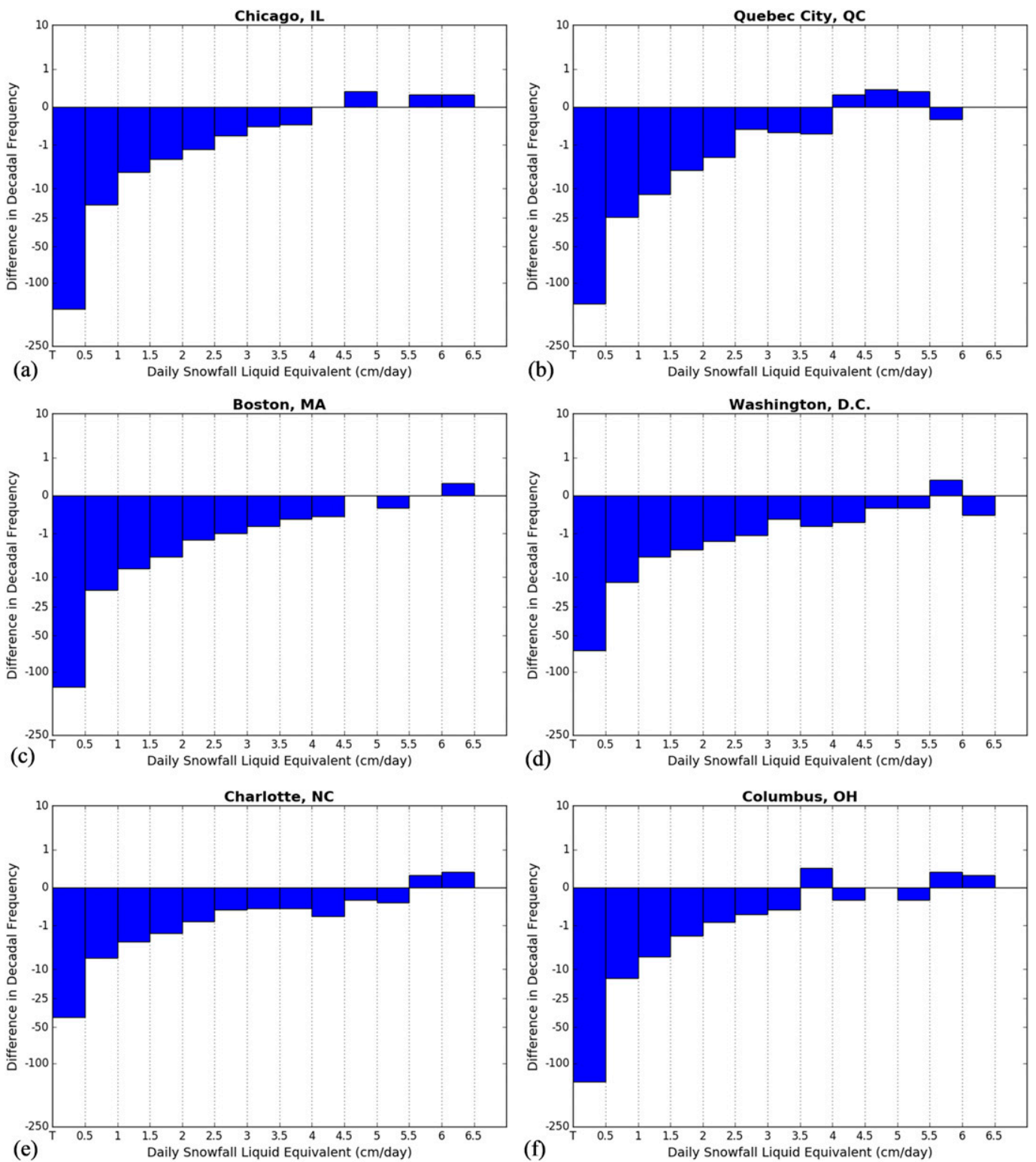

FIG. 7. Histograms that depict changes in the decadal frequency of daily snowfall events as a function of snowfall amount (liquid equivalent) with $\mathrm{CO}_{2}$ doubling for various North American cities: (a) Chicago; (b) Quebec City, Canada; (c) Boston; (d) Washington, D.C.; (e) Charlotte, North Carolina; and (f) Columbus, Ohio. The T signifies a trace amount of $0.0254-\mathrm{cm}$ liquid equivalent.

Figure $9 b$ shows the change in frequency of the 2-day maximum 6-hourly average wind speed exceeding the 1990 control run's 98th percentile. Much of the region does not experience statistically significant changes, with notable exceptions being high-elevation areas, including the Blue Ridge Mountains of Virginia and the White Mountains of New Hampshire and Maine. These areas experience relatively strong decreases in frequency of more than $10 \%$. There are also areas of relatively strong increases of more than $6 \%$ in Ontario. It is important to note that while HSEW events are defined as the two thresholds depicted in Figs. 9a and $9 \mathrm{~b}$ being met, HSEW event frequency ultimately depends on the probability of high snow and extreme wind occurring at the same time, so a change in the frequency of one of the thresholds being met does not necessarily result in an equivalent change in HSEW event frequency. For this reason, it is helpful to look at the change in the ratio of high-snowfall events to HSEW events after 2XC, as depicted in Fig. 10. Most of the changes in the ratio are not statistically significant, indicating that changes in HSEW frequency are not driven by changes in the joint 

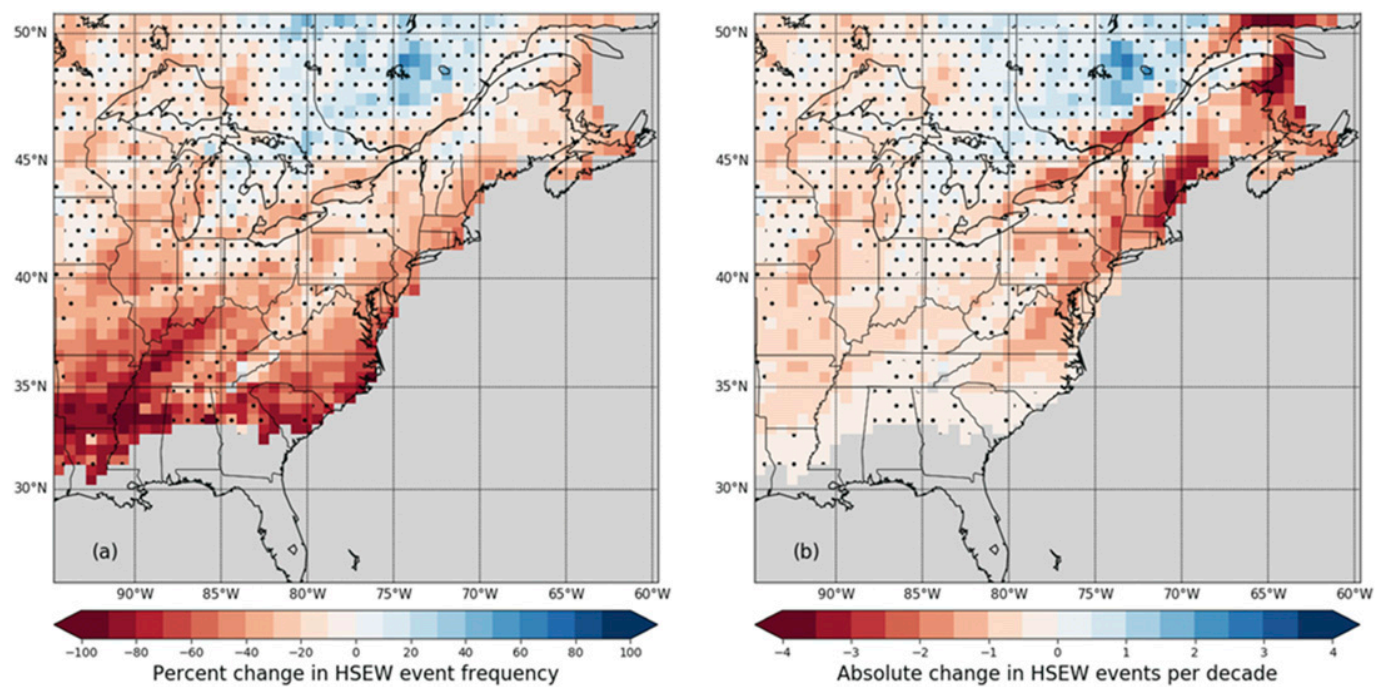

FIG. 8. (a) The percent change in the frequency of unique HSEW events after $\mathrm{CO}_{2}$ doubling. (b) The absolute change in decadal frequency between the two 300-yr runs with $\mathrm{CO}_{2}$ doubling. Stippling indicates regions that do not pass a statistical significance test at the $5 \%$ level when compared to the control simulation. Note that ocean points and areas where $\leq 5 \mathrm{HSEW}$ events occurred in the control run are masked.

probability of extreme winds and high snowfalls occurring simultaneously. This is not true for several regions, including central North Carolina, northern Indiana, and southeastern Canada, where there are statistically significant increases in the ratio of HSEW events to qualifying high snowfalls. The area of ratio increase in northern Indiana corresponds to an area of insignificant changes in HSEW event frequency in Fig. 8, implying that any increases in the proportion of high snowfalls that qualify as HSEW events is offset by decreases in high-snowfall frequency in Fig. 9. Although central North Carolina experiences increases in the ratio with $2 \mathrm{XC}$, it also experiences significant decreases in HSEW frequency, implying that the reduction in highsnowfall events is the driving force behind the decrease in HSEW events.
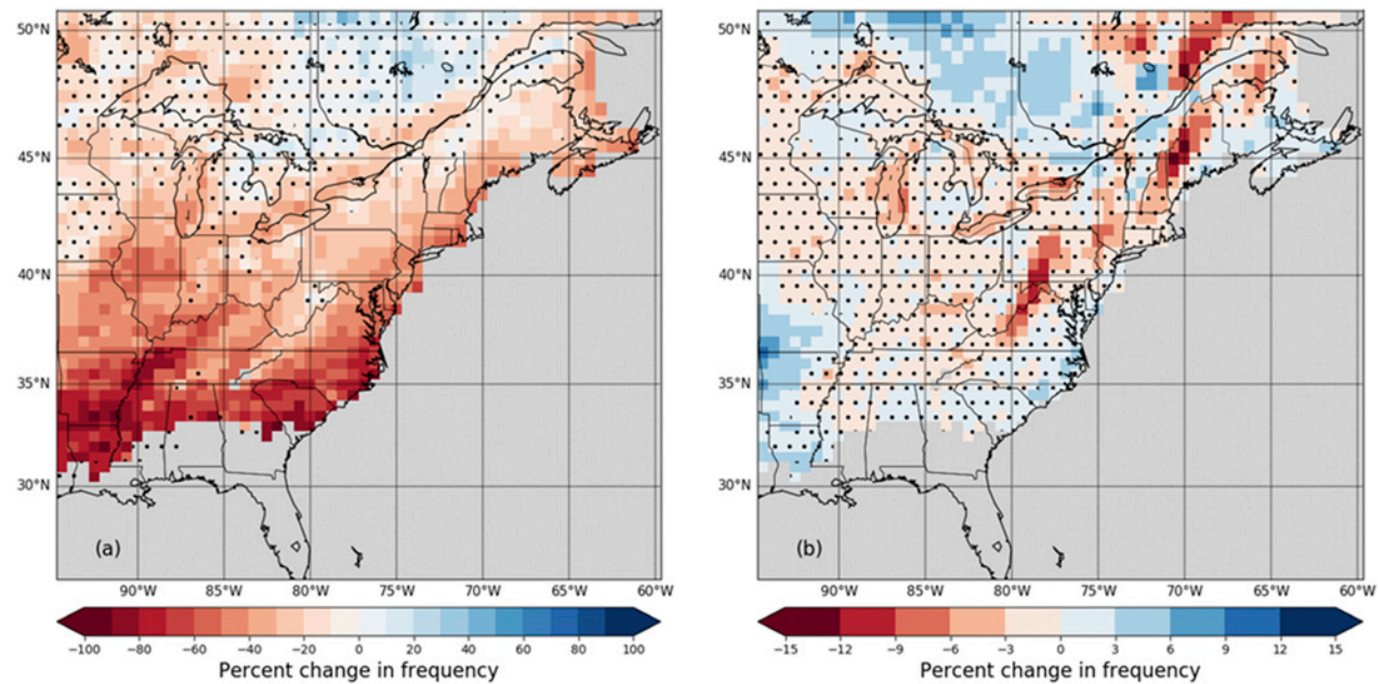

FIG. 9. (a) The change in the frequency of unique 2 -day snowfalls $\geq 2.5$-cm liquid equivalent. Grid boxes with $\leq 5$ two-day snowfalls meeting this criterion in the control run are masked. (b) The change in frequency of the 2-day maximum 6-hourly average winds exceeding the control run's 98th percentile. Stippling indicates regions that do not pass a statistical significance test at the $5 \%$ level when compared to the control simulation. Areas with $\leq 5$ HSEW events in the control run are masked. Ocean points are also masked for both plots. 


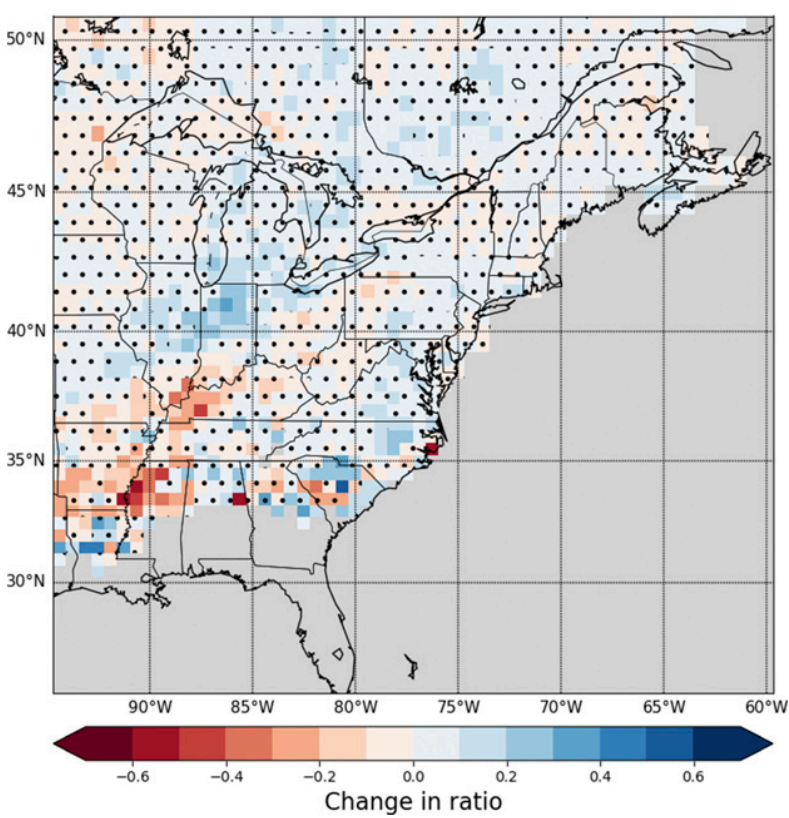

FIG. 10. The change in the ratio of high-snow events to HSEW events with $2 \mathrm{XC}$. Areas with $\leq 5 \mathrm{HSEW}$ events and ocean points are masked. Stippling indicates regions that do not pass a statistical significance test at the $5 \%$ level when compared to the control simulation.

A sensitivity analysis was performed to determine if the choice of wind and snow thresholds affects the resulting changes in HSEW events with $\mathrm{CO}_{2}$ doubling. Figures $11 \mathrm{a}-\mathrm{d}$ are directly comparable to Fig. 8a but with varying snowfall and wind thresholds. For Figs. 11a and $11 \mathrm{~b}$, changing the snowfall threshold to 2 or $3 \mathrm{~cm}$ does not alter the spatial pattern of event frequency changes but instead results in subtle shifts. Choosing a higher snowfall threshold reduces the magnitude of HSEW event decreases and increases the magnitude of HSEW event increases, with the opposite response when a lower snowfall threshold is chosen. Varying the wind threshold, as was done in Figs. 11c and 11d by setting it to the 95th and 99th percentile of the control's 2-day maximum 6-hourly winds, appears to increase the magnitude of changes in HSEW event frequency with progressively more extreme percentiles for wind threshold choices. Increasing either the snowfall or wind threshold amplifies the contrast between the increases in northern interior regions and the decreases in southern and coastal regions.

Many of the spatial patterns of snowfall and HSEW changes appear to be strongly dependent on temperature. To further explore the relationship between temperature and changes in snowfall with increasing $\mathrm{CO}_{2}$ atmospheric concentrations, the mean winter temperature for the control run was calculated by averaging monthly average 2-m temperatures for December,
January, and February. A scatterplot of the percent change in mean annual snowfall with $2 \mathrm{XC}$ versus the mean winter temperature in the control is shown in Fig. 12a. Areas with relatively warm mean winter temperatures experience the greatest decreases in mean annual snowfall with $2 \mathrm{XC}$, while the smallest decreases occur in grid boxes with the coldest winter temperatures. A similar pattern is detected in Fig. 12b, where the percent change in frequency of unique $\geq 2.5$-cm 2-day snowfalls is plotted against the mean winter surface temperature in the control run. In both plots, points where the changes in mean or extreme snowfall are not statistically significant are excluded from the linear regression. Figures $12 \mathrm{a}$ and $12 \mathrm{~b}$ are consistent with the relationship of mean and extreme snowfall response and climatological temperature in the control climate shown in O'Gorman (2014) and Kawase et al. (2016). Grid boxes with the coldest average winter temperatures tend to experience either the greatest increases in $\geq 2.5$-cm event frequency or the smallest decreases. The range of extreme snowfall changes for a given climatological temperature, however, is considerably larger than for mean-snowfall changes. For example, regions with a climatological winter temperature between $-15^{\circ}$ and $-10^{\circ} \mathrm{C}$ in the control simulation experience changes in the frequency of $\geq 2.5-\mathrm{cm}$ snowfall events ranging from about $-40 \%$ to about $+50 \%$. The change in mean annual snowfall only ranges from about $-25 \%$ to $-10 \%$.

The difference between changes in the mean and extreme snowfall highlights that although changes in mean snowfall can mainly be explained by temperature alone, snowfall extremes are less thermodynamically constrained. This was found in the theoretical work of O'Gorman (2014): the theory for changes in extreme snowfall did not hold over high-elevation regions, which are also colder and experience dynamical processes that lead to snowfall enhancement like orographic precipitation. However, in this study, when high-elevation points were excluded in the linear regression, the amount of variance explained by the regression did not change considerably. Likewise, the exclusion of low-lying grid boxes did not improve $R^{2}$, implying that elevation may not be a good additional predictor for this region.

\section{Summary}

The primary focus of this study is the change in HSEW events with $\mathrm{CO}_{2}$ doubling, which are intended to represent disruptive snowstorms with heavy snow and strong winds in a region known for powerful snowstorms (Changnon 2007). The analysis of HSEW events reveals consistency with the snowfall trends observed in O'Gorman (2014), Krasting et al. (2013), Kapnick and 

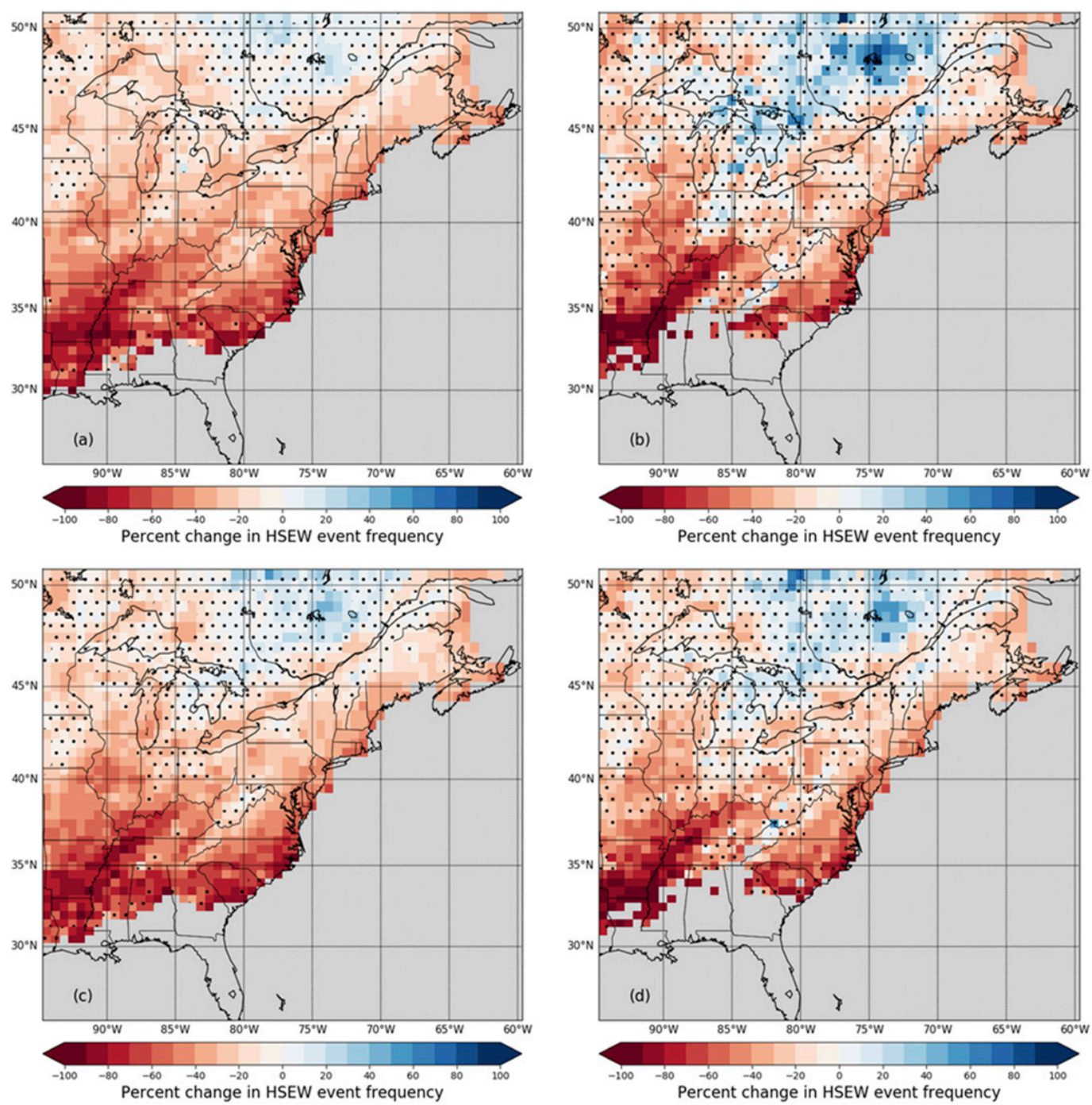

FIG. 11. (a) Percent change in HSEW events with $\mathrm{CO}_{2}$ doubling using a 2-cm liquid equivalent threshold instead of $2.5 \mathrm{~cm}$. (b) As in (a), but for a 3-cm threshold. (c) Percent change in HSEW events with $\mathrm{CO}_{2}$ doubling using the 95th percentile of 2-day maximum 6-hourly average winds threshold. (d) As in (c), but for the 99th percentile. Stippling indicates regions that do not pass a statistical significance test at the $5 \%$ level when compared to the control simulation. Note that areas where $\leq 5$ HSEW events according to the definition outlined in the plot in the control run are masked as well as ocean points.

Delworth (2013), and Danco et al. (2016) but with the use of a higher-atmospheric-resolution GCM. It expands on that work and that of Kapnick and Delworth (2013) by incorporating extreme-wind and snowfall metrics for the purpose of understanding blizzard-like storms. Based on the results of the two CM2.5 FLOR simulations, the entire study area is projected to experience decreases in mean annual snowfall, although the strength of the decrease is dependent on latitude and elevation of the area considered. The mean winter temperature is an accurate predictor of the magnitude of annual snowfall decreases, which is consistent with the relationship found in Krasting et al. (2013), O’Gorman
(2014), Danco et al. (2016), and Kawase et al. (2016). The southeastern United States, especially coastal areas, shows the largest decreases, whereas mean snowfall in southeastern Canada and the Appalachian region decreases the least. The response of snowfall to $\mathrm{CO}_{2}$ forcing is complex because it is determined by both the responses of precipitation and temperature; increasing average surface temperatures may reduce the fraction of precipitation that falls as snow, but increased precipitation, which has been projected for almost the entire study area, would act against the temperature change impact (Trenberth 2011). In high-latitude or high-elevation areas, air temperatures may remain cold 

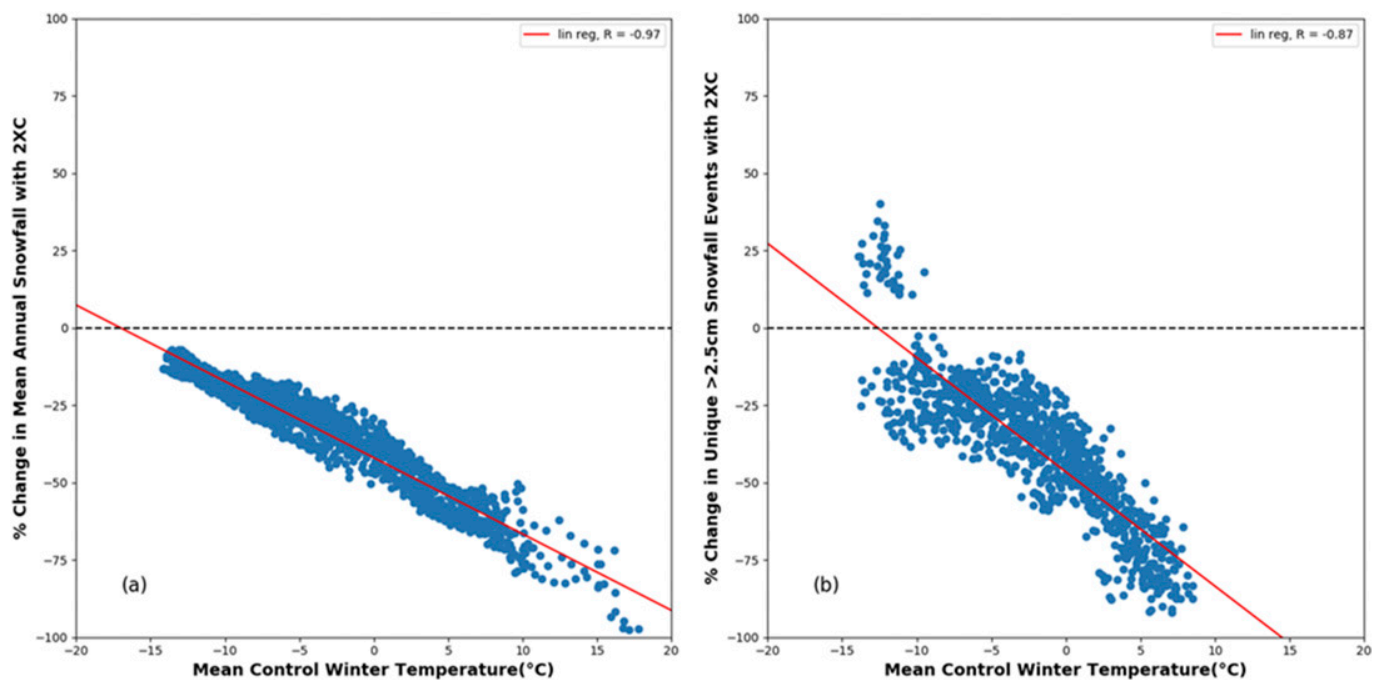

FIG. 12. (a) Scatterplot of the percent change in mean annual snowfall with $\mathrm{CO}_{2}$ doubling vs the mean control winter (DJF) temperature in the control run. (b) As in (a), but the percent change in unique 2-day snowfalls $\geq 2.5-\mathrm{cm}$ liquid equivalent with $\mathrm{CO}_{2}$ doubling. Note that grid boxes containing more than $50 \%$ ocean are masked. The correlation coefficient between the actual and linearly regressed values $R$ is indicated in the top right of each panel. Points that do not pass a statistical significance test at the $5 \%$ level are not included.

enough to support snow at a high frequency, supporting the relatively small decreases in mean snowfall. This result is consistent with Kapnick and Delworth (2013) and Krasting et al. (2013), which both find that enhanced precipitation in these areas partially compensates for a decrease in the fraction of precipitation falling as snow, allowing for this muted snowfall response when compared to other areas in the midlatitudes. The reductions in mean annual snowfall with increased $\mathrm{CO}_{2}$ are consistent with the trends found in previous studies (Kapnick and Delworth 2013; Krasting et al. 2013; O'Gorman 2014; Danco et al. 2016; Kawase et al. 2016).

The changes in extreme percentiles of daily snowfall are less negative for nearly all of the study area when compared to the changes in mean snowfall after $\mathrm{CO}_{2}$ doubling. Certain regions such as southeastern Canada and the northeastern United States experience positive changes in the 99.9th, 99.95th, and 99.99th percentiles of daily snowfall, implying the potential for more intensesnowfall events in the future climate. The southeastern United States shows the opposite trend: fractional decreases in extreme percentiles of 2-day snowfall are greater in magnitude than the reductions in annual snowfall. The change in frequency of $\geq 2.5$ - $\mathrm{cm}$ liquid equivalent events was also considered because of its relevance to this study's definition of HSEW events, which shows a spatial distribution consistent with the changes in extreme percentiles of daily snowfall. The decreases in mean snowfall and muted extreme response were also found in O'Gorman (2014) and Danco et al. (2016), which both found regions of southern Canada where extreme event frequency are projected to increase despite decreases in mean- and low-snowfall event frequency. O'Gorman (2014) reasoned that the responses of mean and extreme snowfall differ because of the insensitivity of the optimal temperature at which extreme-snowfall events occur, and the findings in this study support the past findings of muted extreme response. Cohen et al. (2018) found increases in major snowfalls for several major cities since 1950 in observations and links this change to the warming Arctic.

HSEW events were defined in this study to combine the two elements that define a blizzard. While it is not feasible to apply the operational definition of blizzard to climate model output because of issues related to spatial and temporal resolution, HSEW events incorporate high snowfall and extreme wind into their definition, which are impactful on their own but pose the most danger to human life and property together. The pattern of HSEW changes with $\mathrm{CO}_{2}$ doubling appears to be mainly determined by the changes in the frequency of the 2-day snowfall threshold being met, with the change in winds having a secondary effect. However, in certain regions, such as Michigan and Indiana, the decrease in HSEW events is smaller in magnitude than the decrease in $\geq 2.5$-cm liquid equivalent 2-day snowfalls, signifying that a greater proportion of heavy-snow events are accompanied by strong winds in these regions with $\mathrm{CO}_{2}$ doubling. This is supported by significant increases in the ratio of HSEW events to high snowfalls in the same areas. The Appalachian Mountains show the opposite trend, with a decrease in HSEW frequency greater than 
the decrease in frequency of the snowfall threshold being met, suggesting a decoupling of extreme winds and high-snowfall events. The change in HSEW event frequency does not appear to be especially sensitive to the specific snow or wind threshold chosen.

\section{Discussion}

In contrast with previous studies, we have focused on changes in the joint probability of high snowfall and extreme wind in an attempt to diagnose changes in blizzard frequency in the future climate. This study makes several crucial assumptions that have the potential to impact results. Because of the use of snow water equivalent, instead of snow depth, areas with typically high snow-to-liquid ratios, such as areas with lake-effect snow or the central United States, may have impactful events that are not captured by a $2.5-\mathrm{cm}$ liquid equivalent snowfall threshold. Including a more realistic treatment of the snow-to-liquid ratio is complicated by the possibility that the ratio may change in a future climate because of its dependence on factors such as temperature profiles. To truly capture significant snowfall events, it may be necessary to develop a snow-toliquid ratio algorithm based on other model output variables or to have snowfall in climate models expressed in terms of the depth of fallen snow (Roebber et al. 2003) rather than liquid equivalent.

Danco et al. (2016) cited the potential problems with insufficient resolution in CMIP5 models and suggested using a high-resolution model to better capture orographic effects on snowfall. While CM2.5 FLOR still faces resolution limitations, it is a significant improvement over past global models available in CMIP5 and may be better able to capture snowfall extremes as well as smaller-scale processes, such as lake-effect snow. However, an ensemble of models with similar resolutions may be better able to capture anticipated changes in snowfall and wind in a changing climate by averaging out discrepancies in any individual model. As resolution improves, it is likely that extreme snowfall and wind events will be better captured and a more rigorous definition of a blizzard-like storm applicable to model output may be developed.

We do not wish to overstate FLOR's ability to resolve mesoscale processes, including orographically enhanced and lake-effect snow. Notaro et al. (2015) finds local maxima in decreases in mean annual snowfall in lakeeffect-prone regions in New York and Pennsylvania by the end of the century using two dynamically downscaled GCMs. Although this study used equilibrium responses under $2 \mathrm{XC}$, FLOR does not produce a similar spatial pattern of decreases in the Great Lakes region.
Statistical downscaling techniques, regional climate models, and improved convective parameterization may allow for better modeling of changes in mesoscale processes in the future climate.

The use of a wind speed threshold based on a specific percentile from the frequency distribution of wind speed in the control simulation is not ideal. For example, if one region is especially windy because of spatial variations in the climatology of atmospheric circulation, the percentile approach will not yield a higher frequency of extreme winds in that region. But the use of a uniform wind speed threshold was also found to be problematic. The $10-\mathrm{m}$ wind speed in the model is quite sensitive to the prescribed surface roughness, which is a function of the large-scale land surface type. This sensitivity results in $10-\mathrm{m}$ wind speeds that have unrealistically sharp gradients at the boundaries between different land surface types. Furthermore, observed 10-m wind speeds are essentially standardized because they are almost exclusively measured at airports where surface roughness is unusually low, reducing the sensitivity to surface type. Perhaps future models should provide a diagnostic calculation of $10-\mathrm{m}$ wind in a low-roughness environment that would be more directly comparable with observed wind speeds, which are used in the operational definition of blizzard conditions.

There are other situations in which blizzard conditions can occur that would not be captured by the definition of an HSEW event used in this study. In areas with relatively low relief and few trees, "ground blizzards" can occur when high winds blow over freshly fallen snow. The HSEW definition does not account for such events when the time between the snowfall and the occurrence of strong winds is greater than two days.

This investigation of a type of event dependent on satisfying several meteorological conditions can be applied to many other meteorological phenomena that depend on the joint probability of several occurrences. For example, wind chill depends on wind speeds and ambient air temperature, and fire weather depends on humidity and temperature. Studies of similar events have already been performed. For example, Delworth et al. (1999) examined future changes in heat index, which is determined by a combination of temperature and dewpoint. Van der Wiel et al. (2017) defines mild weather as an event that depends on daily total precipitation, daily maximum air temperature, and daily mean dewpoint temperatures being within certain ranges of acceptability. Investigations of these types of events may encounter similar complications in applying operational definitions to model output or, such as in the case of mild weather, may be subjective and based on human perception and impacts. However, as models 
improve to capture basic statistics of climate variables and regional differences in climate through increased resolution, they can be employed as tools to explore weather-related events that matter for human activities (van der Wiel et al. 2017; Marotzke et al. 2017).

In addition to the mapped regional changes in extremes, we also explored changes in local extremes for a select number of cities. We find that while the number of HSEW events decline in most places, daily snowfall extremes exhibit an increase in many cities. This complicates the interpretation of the broader applications of our results: while the defined "blizzard-like" storms (HSEW) decrease for much of the study area, extreme snowfall increases above certain thresholds. Depending on what type of storm has the greater impact in a particular location, the HSEW or changes in daily snowfall distributions may be more useful. More generally, this implies that when dealing with extreme snowfall and blizzard-like storms, the definition of extreme event matters for how it changes with climate forcing. Careful definitions and communication of storm characteristics are necessary to avoid study findings being misinterpreted or incorrectly applied to local risks. As the fields of snowrelated extremes and multivariable extremes expand to meet societal needs, caution will have to be taken in exploring how extremes change and how those changes may be interpreted.

Acknowledgments. TJ was supported by a NOAA Hollings Undergraduate Scholarship and related support in kind from NOAA OED and GFDL. The authors gratefully acknowledge comments on an earlier draft from Dennis Adams-Smith and Honghai Zhang, as well as David Robinson for help in acquiring the NorAm dataset. They also acknowledge Bryan Raney for providing computational assistance and Leo Donner for his insight into the microphysics of CM2.5 FLOR.

\section{REFERENCES}

Anderson, J. L., and Coauthors, 2004: The new GFDL global atmosphere and land model AM2-LM2: Evaluation with prescribed SST simulations. J. Climate, 17, 4641-4673, https:// doi.org/10.1175/JCLI-3223.1.

Baxter, M. A., C. E. Graves, and J. T. Moore, 2005: A climatology of snow-to-liquid ratio for the contiguous United States. Wea. Forecasting, 20, 729-744, https://doi.org/10.1175/WAF856.1.

Changnon, S. A., 2007: Catastrophic winter storms: An escalating problem. Climatic Change, 84, 131-139, https://doi.org/10.1007/ s10584-007-9289-5.

Cohen, J., K. Pfieffer, and J. A. Francis, 2018: Warm Arctic episodes linked with increased frequency of extreme winter weather in the United States. Nat. Commun., 9, 869, https:// doi.org/10.1038/s41467-018-02992-9.

Danco, J. F., A. M. DeAngelis, B. K. Raney, and A. J. Broccoli, 2016: Effects of a warming climate on daily snowfall events in the Northern Hemisphere. J. Climate, 29, 6295-6318, https:// doi.org/10.1175/JCLI-D-15-0687.1.

Delworth, T. L., J. D. Mahlman, and T. R. Knutson, 1999: Changes in heat index associated with $\mathrm{CO}_{2}$-induced global warming. Climatic Change, 43, 369-386, https://doi.org/10.1023/ A:1005463917086.

—, and Coauthors, 2012: Simulated climate and climate change in the GFDL CM2.5 high-resolution coupled climate model. J. Climate, 25, 2755-2781, https://doi.org/10.1175/ JCLI-D-11-00316.1.

Diffenbaugh, N., and F. Giorgi, 2012: Climate change hotspots in the CMIP5 global climate model ensemble. Climatic Change, 114, 813-822, https://doi.org/10.1007/s10584-012-0570-x.

Environment and Climate Change Canada, 2016: Public alerting criteria. Environment and Climate Change Canada, accessed 15 January 2017, http://www.ec.gc.ca/meteo-weather/default. asp?lang $=$ En\&n $=$ d9553ab5-1\#blizzard.

Gelaro, R., and Coauthors, 2017: The Modern-Era Retrospective Analysis for Research and Applications, version 2 (MERRA-2). J. Climate, 30, 5419-5454, https://doi.org/10.1175/ JCLI-D-16-0758.1.

Jakob, C., and S. A. Klein, 2000: A parameterization of the effects of cloud and precipitation overlap for use in general circulation models. Quart. J. Roy. Meteor. Soc., 126, 2525-2544, https://doi.org/10.1002/qj.49712656809.

Jia, L., and Coauthors, 2015: Improved seasonal prediction of temperature and precipitation over land in a high-resolution GFDL climate model. J. Climate, 28, 2044-2062, https:// doi.org/10.1175/JCLI-D-14-00112.1.

Jiang, Y.-A., Y. Chen, Y.-Z. Zhao, P.-X. Chen, X.-J. Yu, J. Fan, and S.-Q. Bai, 2013: Analysis on changes of basic climatic elements and extreme events in Xinjiang, China during 19612010. Adv. Climate Change Res., 4, 20-29, https://doi.org/ 10.3724/SP.J.1248.2013.00020.

Kapnick, S. B., and T. L. Delworth, 2013: Controls of global snow under a changed climate. J. Climate, 26, 5537-5562, https:// doi.org/10.1175/JCLI-D-12-00528.1.

Kawase, H., A. Murata, R. Mizuta, H. Sasaki, M. Nosaka, M. Ishii, and I. Takayabu, 2016: Enhancement of heavy daily snowfall in central Japan due to global warming as projected by large ensemble of regional climate simulations. Climatic Change, 139, 265-278, https://doi.org/10.1007/s10584-016-1781-3.

Kluver, D., T. Mote, D. Leathers, G. R. Henderson, W. Chan, and D. A. Robinson, 2016: Creation and validation of a comprehensive $1^{\circ}$ by $1^{\circ}$ daily gridded North American dataset for 1900-2009: Snowfall. J. Atmos. Oceanic Technol., 33, 857-871, https://doi.org/10.1175/JTECH-D-15-0027.1.

Krasting, J. P., A. J. Broccoli, K. W. Dixon, and J. R. Lanzante, 2013: Future changes in Northern Hemisphere snowfall. J. Climate, 26, 7813-7828, https://doi.org/10.1175/ JCLI-D-12-00832.1.

Kunkel, K. E., M. Palecki, L. Ensor, K. G. Hubbard, D. Robinson, K. Redmond, and D. Easterling, 2009: Trends in twentiethcentury U.S. snowfall using a quality-controlled dataset. J. Atmos. Oceanic Technol., 26, 33-44, https://doi.org/10.1175/ 2008JTECHA1138.1.

Lawson, B., 2003: Trends in blizzards at selected locations on the Canadian prairies. Nat. Hazards, 29, 123-138, https://doi.org/ 10.1023/A:1023678823191.

Manabe, S., and R. T. Wetherald, 1975: The effects of doubling the $\mathrm{CO}_{2}$ concentration on the climate of a general circulation model. J. Atmos. Sci., 32, 3-15, https://doi.org/10.1175/ 1520-0469(1975)032<0003:TEODTC >2.0.CO;2. 
Marotzke, J., and Coauthors, 2017: Climate research must sharpen its view. Nat. Climate Change, 7, 89-91, https://doi.org/10.1038/ nclimate3206.

Milly, P. C. D., and Coauthors, 2014: An enhanced model of land water and energy for global hydrologic and Earth-system studies. J. Hydrometeor., 15, 1739-1761, https://doi.org/ 10.1175/JHM-D-13-0162.1.

NWS, 2016a: National Weather Service New York, NY watch warning advisory definitions page. National Weather Service, accessed 6 June 2016, http://www.weather.gov/okx/ wwa_definitions\#winter2.

_ 2016b: National Weather Service glossary. National Weather Service, accessed 6 June 2016, http://w1.weather.gov/glossary/.

Notaro, M., D. Lorenz, C. Hoving, and M. Schummer, 2014: Twenty-first-century projections of snowfall and winter severity across central-eastern North America. J. Climate, 27, 6526-6550, https://doi.org/10.1175/JCLI-D-13-00520.1.

— , V. Bennington, and S. Vavrus, 2015: Dynamically downscaled projections of lake-effect snow in the Great Lakes basin. J. Climate, 28, 1661-1684, https://doi.org/10.1175/ JCLI-D-14-00467.1.

O'Gorman, P. A., 2014: Contrasting responses of mean and extreme snowfall to climate change. Nature, 512, 416-418, https://doi.org/10.1038/nature13625.

—_, and T. Schneider, 2009: The physical basis for increases in precipitation extremes in simulations of 21st-century climate change. Proc. Natl. Acad. Sci. USA, 106, 14 773-14 777, https:// doi.org/10.1073/pnas.0907610106.

Rasmussen, R., and Coauthors, 2012: How well are we measuring snow: The NOAA/FAA/NCAR winter precipitation test bed. Bull. Amer. Meteor. Soc., 93, 811-829, https://doi.org/10.1175/ BAMS-D-11-00052.1.

Roebber, P. J., S. L. Bruening, D. M. Schultz, and J. V. Cortinas Jr., 2003: Improving snowfall forecasting by diagnosing snow density. Wea. Forecasting, 18, 264-287, https://doi.org/10.1175/ 1520-0434(2003)018<0264:ISFBDS > 2.0.CO;2.

Rotstayn, L., 1997: A physically based scheme for the treatment of stratiform clouds and precipitation in large-scale models.
I: Description and evaluation of the microphysical processes. Quart. J. Roy. Meteor. Soc., 123, 1227-1282, https://doi.org/ 10.1002/qj.49712354106.

Schwartz, R. M., and T. W. Schmidlin, 2002: Climatology of blizzards in the conterminous United States, 1959-2000. J. Climate, 15, 1765-1772, https://doi.org/10.1175/1520-0442(2002)015<1765: COBITC $>2.0 . \mathrm{CO} ; 2$.

Squires, M. F., J. H. Lawrimore, R. R. Heim, D. A. Robinson, M. R. Gerbush, and T. W. Estilow, 2014: The regional snowfall index. Bull. Amer. Meteor. Soc., 95, 1835-1848, https://doi.org/ 10.1175/BAMS-D-13-00101.1.

Tiedtke, M., 1993: Representation of clouds in large-scale models. Mon. Wea. Rev., 121, 3040-3061, https://doi.org/10.1175/ 1520-0493(1993)121<3040:ROCILS > 2.0.CO;2.

Trenberth, K. E., 2011: Changes in precipitation with climate change. Climate Res., 47, 123-138, https://doi.org/10.3354/cr00953.

Tucker, W. B., and G. M. Clohan, 1979: Computer simulation of urban snow removal. Snow removal and ice control research, Transportation Research Board Special Research Rep. 185, 293-302.

van der Wiel, K., and Coauthors, 2016: The resolution dependence of contiguous U.S. precipitation extremes in response to $\mathrm{CO}_{2}$ forcing. J. Climate, 29, 7991-8012, https://doi.org/10.1175/ JCLI-D-16-0307.1.

—, S. B. Kapnick, and G. A. Vecchi, 2017: Shifting patterns of mild weather in response to projected radiative forcing. Climatic Change, 140, 649-658, https://doi.org/10.1007/ s10584-016-1885-9.

Vavrus, S., 2007: The role of terrestrial snow cover in the climate system. Climate Dyn., 29, 73-88, https://doi.org/10.1007/ s00382-007-0226-0.

Vecchi, G. A., and Coauthors, 2014: On the seasonal forecasting of regional tropical cyclone activity. J. Climate, 27, 7994-8016, https://doi.org/10.1175/JCLI-D-14-00158.1.

Yang, X., and Coauthors, 2015: Seasonal predictability of extratropical storm tracks in GFDL's high-resolution climate prediction model. J. Climate, 28, 3592-3611, https://doi.org/10.1175/ JCLI-D-14-00517.1. 